ARTICLE

DOI: $10.1038 / s 41467-017-01309-6$

\title{
APOBEC3H structure reveals an unusual mechanism of interaction with duplex RNA
}

Jennifer A. Bohn 1,2, Keyur Thummar (10 3,4, Ashley York ${ }^{3,4}$, Alice Raymond ${ }^{3,4}$, W. Clay Brown', Paul D. Bieniasz ${ }^{3,4}$, Theodora Hatziioannou ${ }^{3} \&$ Janet L. Smith ${ }^{1,2}$

The APOBEC3 family of cytidine deaminases cause lethal hypermutation of retroviruses via deamination of newly reverse-transcribed viral DNA. Their ability to bind RNA is essential for virion infiltration and antiviral activity, yet the mechanisms of viral RNA recognition are unknown. By screening naturally occurring, polymorphic, non-human primate $\mathrm{APOBEC} 3 \mathrm{H}$ variants for biological and crystallization properties, we obtained a 2.24- $\AA$ crystal structure of pig-tailed macaque APOBEC3H with bound RNA. Here, we report that APOBEC3H forms a dimer around a short RNA duplex and, despite the bound RNA, has potent cytidine deaminase activity. The structure reveals an unusual RNA-binding mode in which two APOBEC $3 \mathrm{H}$ molecules at opposite ends of a seven-base-pair duplex interact extensively with both RNA strands, but form no protein-protein contacts. CLIP-seq analysis revealed that APOBEC3H preferentially binds to sequences in the viral genome predicted to contain duplexes, a property that may facilitate both virion incorporation and catalytic activity.

\footnotetext{
${ }^{1}$ Life Sciences Institute, University of Michigan, Ann Arbor, MI 48109, USA. ${ }^{2}$ Department of Biological Chemistry, University of Michigan, Ann Arbor, MI 48109, USA. ${ }^{3}$ Laboratory of Retrovirology, The Rockefeller University, New York, NY 10065, USA. ${ }^{4}$ Howard Hughes Medical Institute, The Rockefeller University, New York, NY 10065, USA. Correspondence and requests for materials should be addressed to T.H. (email: thatziio@rockefeller.edu) or to J.L.S. (email: JanetSmith@umich.edu)
} 
POBEC3 (apolipoprotein B mRNA-editing enzyme, catalytic polypeptide-like, family 3; “A3”) antiviral proteins ${ }^{1}$ cause lethal G-to-A hypermutation in retroviruses and retroelements by converting deoxycytosine to deoxyuracil in newly reverse-transcribed single-stranded DNA (ssDNA) ${ }^{2}$. Primate genomes encode seven $\mathrm{A} 3$ proteins, of which at least three $(\mathrm{A} 3 \mathrm{~F}, \mathrm{~A} 3 \mathrm{G}$, and $\mathrm{A} 3 \mathrm{H})$ inhibit human immunodeficiency virus (HIV-1) replication, but are antagonized by the viral Vif accessory protein in a species-dependent manner ${ }^{3-5}$. A3 proteins are comprised of one $(\mathrm{A} 3 \mathrm{H})$ or two (A3F and $\mathrm{A} 3 \mathrm{G})$ " $\mathrm{Z}$ " domains containing $\mathrm{Zn}$-coordinating $\mathrm{His}$ and Cys amino acids that, together with a conserved Glu, form the deaminase catalytic center $^{2}$. Among the three identified Z-domain clades (Z1-Z3), $\mathrm{A} 3 \mathrm{~F}$ and $\mathrm{A} 3 \mathrm{G}$ are comprised of $\mathrm{Z1}$ and $\mathrm{Z} 2$ domains, while $\mathrm{A} 3 \mathrm{H}$ is unique among primate $\mathrm{A} 3$ proteins in possessing a single $\mathrm{Z} 3$ domain $^{2}$.

RNA binding is a key feature of A3 proteins that is necessary for their encapsidation into virions and for antiviral activity ${ }^{6,7}$. Although the mechanisms by which $\mathrm{A} 3 \mathrm{~s}$ recognize RNA are unknown, they are sufficiently non-specific that widely divergent RNA sequences are recognized, yet they exhibit sufficient selectivity to enable virion RNA binding and incorporation in the presence of a vast excess of cellular RNA ${ }^{8,9}$. A3 binding to RNA may also contribute to the deaminaseindependent ability to inhibit HIV-1 reverse transcriptase (RT) 10-13. In addition, $\mathrm{A} 3 \mathrm{H}$ and the RNA-binding domains of $\mathrm{A} 3 \mathrm{~F}$ and $\mathrm{A} 3 \mathrm{G}$ drive the formation of higher-order oligomeric complexes ${ }^{14,15}$. RNA binding is thought to inhibit deaminase activity, via an unknown mechanism ${ }^{13,16,17}$, and in the two-domain $\mathrm{A} 3 \mathrm{~F}$ and $\mathrm{A} 3 \mathrm{G}$ proteins, one $\mathrm{Z}$-domain binds RNA and the other catalyzes cytidine deamination ${ }^{2}$. Crystal structures obtained for the isolated catalytic domains of $\mathrm{A} 3 \mathrm{~F}$ and $\mathrm{A} 3 \mathrm{G}$ and for an A3G RNA-binding domain reveal a common domain structure and Zn-binding site ${ }^{18-22}$. Nevertheless, in each case, the A3 protein was extensively truncated or engineered to improve stability or crystallization properties. The structure of an unmodified huA3C has also been obtained $^{23}$, however, this protein lacks antiviral activity. Therefore, thus far, no structure is available for a naturally occurring, full-length APOBEC3 with antiviral activity, and the structural basis for RNA recognition by any APOBEC3 is unknown.

Here, we present the $2.24-\AA$ crystal structure of a full-length, natural polymorphic variant of pig-tailed macaque APOBEC $3 \mathrm{H}$ (pgtA $3 \mathrm{H})$ bound to a short RNA duplex. Furthermore, we show that human $\mathrm{A} 3 \mathrm{H}$ haplotype II (huA3H) and several pgtA $3 \mathrm{H}$ variants retain cytidine deaminase activity in the presence of bound RNA, demonstrating that the RNA does not obstruct access to the $\mathrm{A} 3 \mathrm{H}$ active site. CLIP-seq analysis reveals that the regions of the viral genome most frequently bound by $\mathrm{A} 3 \mathrm{H}$ are predicted to form short duplex structures. These results illuminate important elements of RNA recognition and potential mechanisms of antiviral activity by a natural, catalytically competent pgtA3H. a

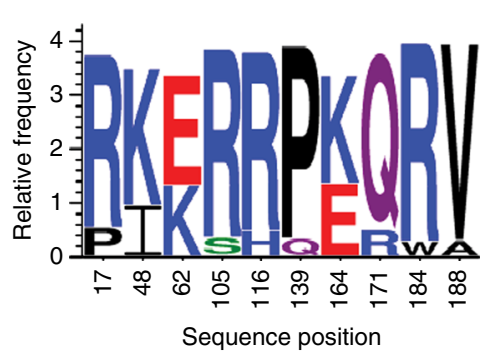

C

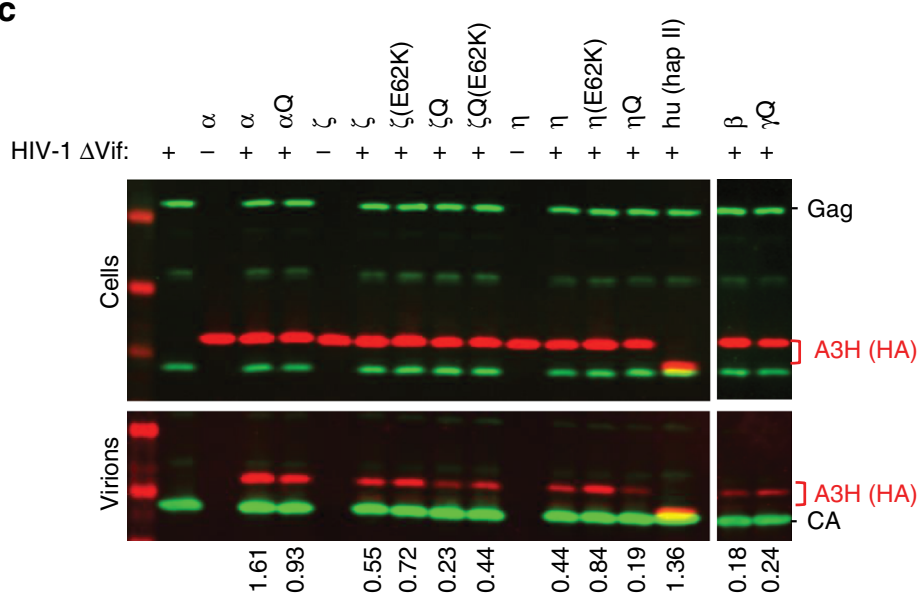

b

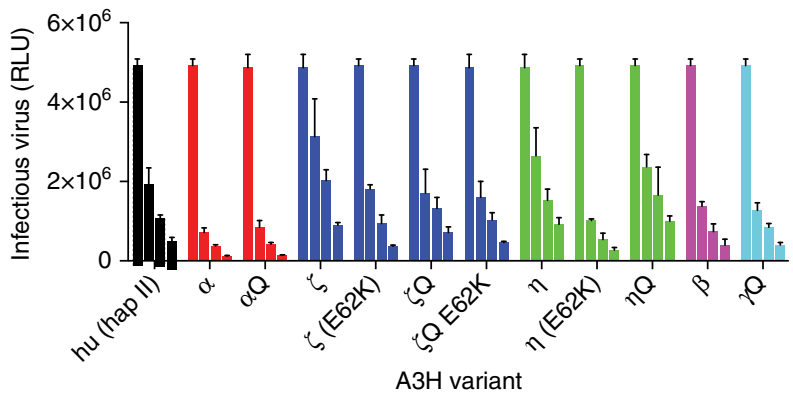

$\mathrm{A} 3 \mathrm{H}$ variant

Fig. $1 \mathrm{~A} 3 \mathrm{H}$ amino acid polymorphism. a Logo representation of $\mathrm{A} 3 \mathrm{H}$ variants obtained from 14 pigtail macaques. Ten sites of variation were identified and at least 13 allelic variants were identified due to variation at multiple sites in some animals (Supplementary Fig. 1). b Antiviral activity of pgtA3H variants compared to huA3H (hap II). HIV-1 $\Delta$ Vif stocks were generated in the presence of increasing amounts of each $\mathrm{HA}$-tagged $\mathrm{A} 3 \mathrm{H}$ variant $(0,37,75,150 \mathrm{ng}$ expression plasmid) and titrated on indicator cell lines expressing nanoluciferase under the control of the HIV promoter. Luciferase activity was measured and expressed as relative light units (RLUs). Mean and standard deviation of $n=2$ independent experiments. c Virion incorporation of $\mathrm{A} 3 \mathrm{H}$ variants. 293T cells stably expressing HA-tagged A3H variants were infected with HIV- $1 \Delta$ Vif. Infected cells and sucrose purified virion particles were analyzed by immunoblot. The specificity of virion incorporation was verified using supernatants from uninfected cells expressing selected $\mathrm{A} 3 \mathrm{H}$ variants. Levels of $\mathrm{A} 3 \mathrm{H}$ virion incorporation are shown under the gels and expressed as the ratio of the signals (arbitrary units) of A3H bands over viral capsid protein (CA) bands 


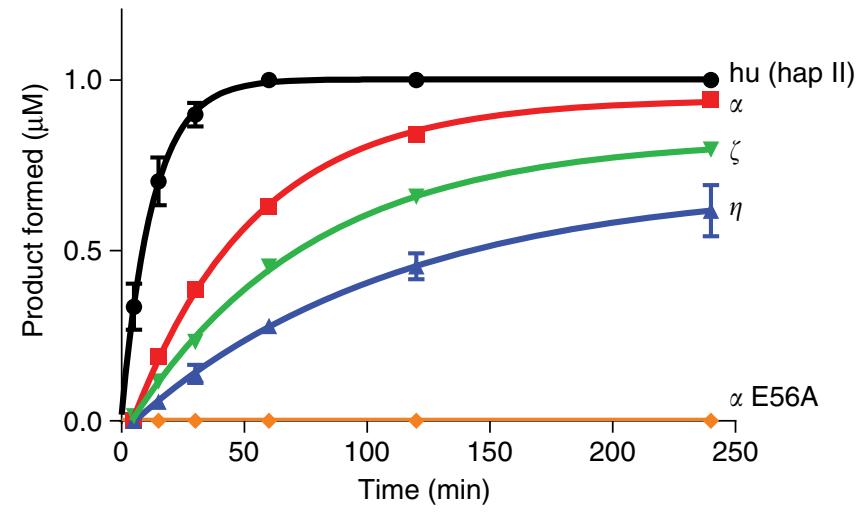

Fig. 2 Cytidine deaminase activity of recombinant $A 3 \mathrm{H}$ variants. Singlestranded DNA $(1 \mu \mathrm{M})$ containing a single reactive cytosine base was combined with $100 \mathrm{nM} \mathrm{A3H}$ coupled with $40 \mathrm{nM}$ uracil deglycosylase, and products were detected by denaturing gel electrophoresis. The active site mutant pgtA3H $\alpha \mathrm{E}^{2} 6 \mathrm{~A}^{13}$ was used as a negative control for $\mathrm{A} 3 \mathrm{H}$

deaminase activity; no activity was detected. Mean and standard deviation of $n=3$ experiments. Initial rates are reported in Table 1

\section{Results}

Naturally occurring polymorphisms in pig-tailed macaque A3H. $\mathrm{A} 3 \mathrm{H}$ is an attractive target for biochemical and structural study because the single $\mathrm{Z3}$ domain possesses all three biochemical activities: cytidine deaminase, RNA binding, and Vif binding. Seven $\mathrm{A} 3 \mathrm{H}$ haplotypes (hap) have been identified in humans, but only three (hap II, hap V, hap VII) restrict HIV$1^{24,25}$. Because our initial attempts to crystallize human (hu) $\mathrm{A} 3 \mathrm{H}$ hap II were unsuccessful, we explored natural $\mathrm{A} 3 \mathrm{H}$ variants encoded by non-human primates, specifically pig-tailed macaques (pgt). Remarkably, analysis of pgtA3H sequences from 14 macaques revealed no less than 13 allelic variants, each of which was expressed as two spliced isoforms that included or excluded a Gln182 codon at the exon 4/5 boundary (26 natural protein variants, Fig. 1a, Supplementary Fig. 1). Analysis of eight naturally occurring pgtA $3 \mathrm{H}$ protein variants revealed similar expression levels in transfected cells and modest variations in levels of virion encapsidation, and in antiviral activity, compared to huA3H (hap II) (Fig. 1b, c). Specifically, greater antiviral potency was generally associated with pgtA3H variants encoding Lys62 $(\alpha, \beta, \gamma)$ as opposed to Glu62 $(\zeta, \eta)$, and introduction of Lys62 in variants $\zeta$ and $\eta$ increased their antiviral activity (Fig. 1b). In addition, the presence of Gln182 marginally enhanced antiviral activity in variant $\zeta$ (Fig. 1b). The levels of antiviral activity generally correlated with the levels of incorporation into particles.

Cytidine deaminase activity of $\mathbf{A 3 H}$. Recombinant full-length, native-sequence huA $3 \mathrm{H}$, pgtA $3 \mathrm{H} \alpha$, pgtA $3 \mathrm{H} \zeta$, and pgtA $3 \mathrm{H} \eta$ expressed in bacteria adopted a mixture of oligomeric states, as detected by gel filtration (Supplementary Fig. 2a), and co-purified with a substantial amount of nucleic acid that was sensitive to RNase but not DNase. Attempts to remove the RNA were not successful, but extensive RNase A treatment resulted in a monodisperse preparation with an apparent molecular weight of $60 \mathrm{kDa}$, suggesting the presence of a dimeric complex of $25.2 \mathrm{kDa}$ polypeptides (Supplementary Fig. $2 \mathrm{~b}, \mathrm{c}$ ). This is consistent with a report of the oligomer state of a recombinant MBP-huA3H fusion protein from an Escherichia coli expression system $^{26}$ and recombinant huA3H from an insect-cell expression system ${ }^{27}$. The complex also contained bound RNA with a length of 10-12 nt, determined by denaturing gel electrophoresis (Supplementary Fig. 2d). All purified A3Hs were catalytically active on a 40-nt ssDNA substrate, in which the reactive cytosine is preceded by a
Table 1 Initial rates of $\mathbf{A} 3 \mathrm{H}$ cytidine deamination

\begin{tabular}{|c|c|}
\hline АЗН & Initial rate (per min) \\
\hline hu (hap II) & $1.46 \pm 0.01$ \\
\hline pgta & $0.15 \pm 0.01$ \\
\hline 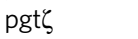 & $0.087 \pm 0.006$ \\
\hline 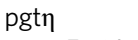 & $0.055 \pm 0.008$ \\
\hline pgt $\alpha$ E56A & No activity \\
\hline
\end{tabular}

thymidine $\left(5^{\prime}-\mathrm{TC}-3^{\prime}\right)$ (Fig. 2, Table 1, Supplementary Fig. 3a, Supplementary Note 1). The differences in the in vitro deaminase activity between the $\mathrm{A} 3 \mathrm{H}$ proteins did not precisely correlate with the antiviral activity of each protein (compare Fig. 1b to Fig. 2, Table 1). This could be attributed to: (1) deaminase-independent mechanisms of viral inhibition ${ }^{13}$ that may differ among the $\mathrm{A} 3 \mathrm{H}$ variants, and (2) the use of the same 40-nt DNA substrate for the in vitro deaminase assays that may not account for any subtle differences in substrate sequence preference between the $\mathrm{A} 3 \mathrm{H}$ variants. For example, the activity of huA3H (hap II) varied by twofold with substrates differing in the +2 position relative to the reactive cytosine ${ }^{26}$. The variation in activity was not due to differences in $\mathrm{Zn}$ incorporation among the $\mathrm{A} 3 \mathrm{H}$ variants. We confirmed that each $\mathrm{A} 3 \mathrm{H}$ variant was purified with a full complement of $\mathrm{Zn}$ by comparing activities of samples with and without added $\mathrm{Zn}$. For each variant, the deaminase activity was identical in parallel assays with and without added $\mathrm{Zn}$ (Supplementary Fig. 3b).

The ability of all purified $\mathrm{A} 3 \mathrm{H}$ variants with bound RNA to maintain deaminase activity demonstrates that the bound RNA does not obstruct access of DNA to the active site, indicating that it is possible for both DNA and RNA oligonucleotides to bind $\mathrm{A} 3 \mathrm{H}$ simultaneously. We further tested whether ribonuclease treatment is critical to deaminase activity, as has been reported for $A 3 H^{13}$ and $A 3 G^{10-12}$. The huA $3 H$ and pgt $A 3 H \zeta$ were purified in absence of added RNase A. Duplicate samples were then incubated with or without RNase A and assayed. All samples had substantial deaminase activity, with twofold greater activity in the ribonuclease-treated A3H. (Supplementary Fig. 3c, Supplementary Note 1).

Structure of a pgtA3H-RNA complex. We attempted crystallization with each of the four purified recombinant $\mathrm{A} 3 \mathrm{H}$ variants, but only pgtA3H $\zeta$ yielded crystals suitable for structure determination. The pgtA3H $\zeta$ structure was solved using the anomalous scattering of the native $\mathrm{Zn}$ ion at the active site of the enzyme, resulting in a high-quality $2.24-\AA$ structure (Fig. 3, Table 2). The refined model is complete except for two amino acids at the $\mathrm{N}$-terminus and $\sim 30$ amino acids at the C-terminus that are present in some non-human primate $\mathrm{A} 3 \mathrm{Hs}$ but not in huA3H (Supplementary Fig. 1) ${ }^{24}$. A3H has the familiar A3 fold composed of a five-stranded central $\beta$-sheet surrounded by six $\alpha$ helices, and is highly similar to structures of other A3s in the overall fold and in the active site ${ }^{18}$ (Supplementary Fig. $4 a, b$ ). Compared to the catalytic domains of $\mathrm{A} 3 \mathrm{~F}$ and $\mathrm{A} 3 \mathrm{G}$ and the RNA-binding domain of A3G, A3H has significant differences in loop 1, loop 3 (proximal to the active site and variable among the four $\mathrm{A} 3 \mathrm{H}$ molecules in the crystal), and in the 15 amino acids preceding the C-terminal helix (Supplementary Fig. 4b, c). Loop 7, which has been implicated in RNA binding ${ }^{13,14,17,28,29}$, is nearly identical in $\mathrm{A} 3 \mathrm{H}$ and the RNA-binding domain of $\mathrm{A} 3 \mathrm{G}$ (Supplementary Fig. 4b). A3H residues implicated in the recognition by Vif proteins ${ }^{30,31}$ are clustered on A3H exposed surfaces, specifically at helices $\alpha 3$ and $\alpha 4$ (Supplementary Fig. 5). 
a

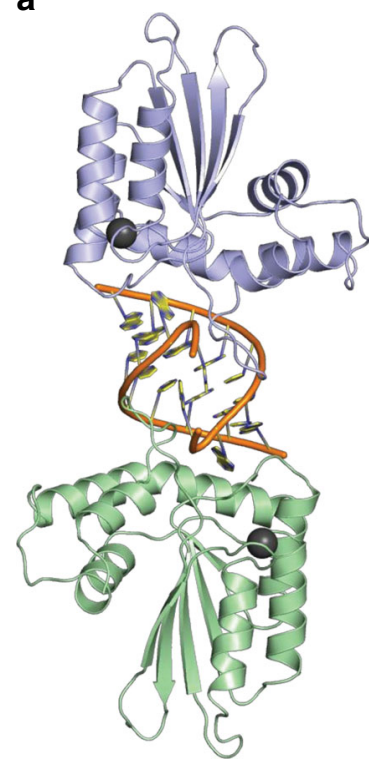

RNA 5'view b

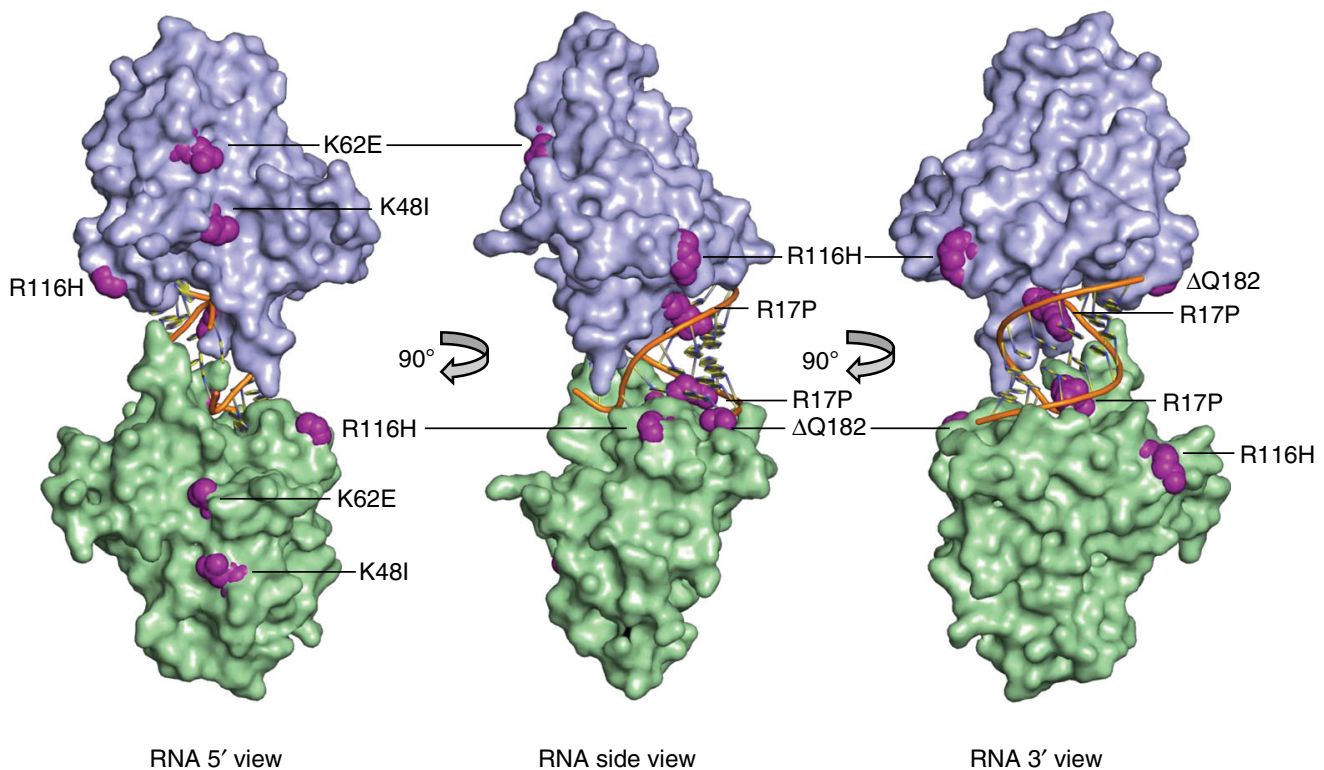

Fig. 3 Crystal structure of pgtA3H -RNA complex. a Two A3H molecules (blue and green cartoon, $\mathrm{Zn}$ as gray sphere) at the ends of a central RNA duplex (orange backbone, yellow bases). b Sites of pgtA3H polymorphic variation. The $\mathrm{A} 3 \mathrm{H}$ surface (colored as in $\mathrm{A}$ ) with sites of variation in magenta. The RNA is nearly engulfed by the two $\mathrm{A} 3 \mathrm{H}$ molecules, which have no direct contacts with each other

Binding of $\mathrm{A3H}$ to the RNA duplex. Surprisingly, $\mathrm{A} 3 \mathrm{H}$ was bound not to ssRNA, but to an RNA duplex. Two A3H molecules form a complex with one RNA duplex (Fig. 3a, b). The crystals contain two such A3H-RNA complexes, which are identical within experimental error excepting the variability in loop 3, which does not contact RNA. The model-unbiased method of structure determination resulted in excellent electron density for the RNA duplex, including the base, ribose, and phosphate for nine nucleotides in each strand (Supplementary Fig. 6a). Refinement after removal of the ribose-specific $2^{\prime}$-hydroxyl atoms from the model resulted in difference electron density for the $2^{\prime}$ hydroxyls, confirming that both strands of the duplex are RNA (Supplementary Fig. 6b). The A3H-RNA complex is maintained solely through protein-RNA contacts; there are no direct contacts between $\mathrm{A} 3 \mathrm{H}$ protein molecules. Rather, each $\mathrm{A} 3 \mathrm{H}$ molecule contacts both strands of the RNA duplex, and together the two A3Hs bury $>40 \%$ of the RNA duplex surface area with a total of $1090 \AA^{2}$ buried at the RNA interface of each A3H molecule (2180 $\AA^{2}$ total in the complex) (Fig. 3).

The A-form duplex in the $\mathrm{A} 3 \mathrm{H}$ complex is typical for RNA (Supplementary Fig. 7a) and for RNA/DNA heteroduplexes (Supplementary Fig. 7b). Of the nine nucleotides in each strand (nt1-9), seven are base paired (nt3-9) and the two $5^{\prime}$ nucleotides (nt1 and nt2) are unpaired. The $3^{\prime}$-end of the RNA terminates in the nt3-nt9 base pair, which is capped by stacking with Trp115 in A3H loop 7 (Fig. 4a) within the ${ }_{110} \mathrm{RLYYHW}_{115}$ putative RNAbinding motif ${ }^{13,14,17,28,29}$. A sharp kink in the RNA between nt1 and nt 2 brings the $5^{\prime}$ nucleotides close to one another and results in stacking of the nt1 bases, which are sandwiched between the phenolic rings of Tyr23 in the two $\mathrm{A} 3 \mathrm{H}$ molecules (Fig. $4 \mathrm{a}$ ). The RNA kink is stabilized by $\mathrm{A} 3 \mathrm{H}$ loop 1 (residues 13-30), which inserts into the narrow major groove of the A-form RNA duplex and includes a unique four-residue insertion $\left({ }_{22} \mathrm{PYYP}_{25}\right)$ (Fig. $\left.4 \mathrm{~b}\right)$. At the tip of loop 1 in each $\mathrm{A} 3 \mathrm{H}$ molecule, cis- $\mathrm{Pro} 22$ positions Tyr23 to stack with the nt1 base of one RNA strand, and Arg26 stabilizes the sharp RNA kink through three hydrogen bonds to the phosphate at the nt1-nt2 bend (Fig. 4b). The only hydrogen bond of $\mathrm{A} 3 \mathrm{H}$ to $\mathrm{RNA}$ not involving a phosphate is between the Tyr113 hydroxyl and the nt2 ribose 2'-hydroxyl (Fig. 4b). The unpaired nt 2 base protrudes into an $\mathrm{A} 3 \mathrm{H}$ "aromatic cage" composed of amino acids from loop 7 (Tyr112, Tyr113, and Trp115) and loop 3 (Trp82) (Fig. 4a, c). These tryptophan and tyrosine side chains form a network of favorable edge-to-face interactions with the nt 2 base, akin to typical interactions of aromatic side chains in protein interiors. In addition to many of these specific interactions, several arginine and lysine side chains hydrogen bond with RNA phosphates and impart a strongly basic character to the $\mathrm{A} 3 \mathrm{H}$ surface that contacts RNA (Supplementary Fig. 8).

In total, each $\mathrm{A} 3 \mathrm{H}$ molecule forms nine hydrogen bonds with the phosphate backbone (six to one strand and three to the other), one hydrogen bond to the nt $22^{\prime}$-hydroxyl, and aromatic interactions with bases in both RNA strands (nt1, nt2, nt3-9 base pair) (Fig. 4). There are no base-specific contacts, consistent with the expected lack of sequence specificity in RNA binding 8,9 . Accordingly, the co-purified RNA lacks a distinct sequence. For each of the seven base pairs, electron density is continuous across the paired bases (Supplementary Fig. 6), that is, either base could be a purine or pyrimidine. In summary, $\mathrm{A} 3 \mathrm{H}$ is selective for RNA through a strong conformational preference for an A-form duplex with seven base pairs, but it lacks sequence specificity.

Binding of $\mathrm{A} 3 \mathrm{H}$ to RNA duplexes in the viral genome. The A3H:RNA complex structure represents a binding mode that should be relevant to the A3H-RNA interaction in virions, leading to the prediction that $\mathrm{A} 3 \mathrm{H}$ may bind preferentially to $7 \mathrm{nt}$ RNA duplexes in the viral genome during encapsidation. Because amino acids that contact RNA are conserved in huA3H and pgtA $3 \mathrm{H}$, we analyzed CLIP-Seq data obtained using virionencapsidated huA $3 \mathrm{H}^{8}$. The ten most frequently bound sites in the viral genome all contained one or two predicted RNA duplexes of seven or more nucleotides (Fig. 5a, Supplementary Fig. 9), while only 2 of 10 control sites with low-frequency $\mathrm{A} 3 \mathrm{H}$ binding contained predicted $7 \mathrm{nt}$ duplexes ( $p=0.0007$, Fig. 5b). The HIV $-15^{\prime}$ leader, particularly, the poly-A stem loop and sequences 
Table 2 Data collection and refinement statistics

\begin{tabular}{|c|c|c|}
\hline & Native $^{a}$ & Zn anomalous ${ }^{b}$ \\
\hline \multicolumn{3}{|l|}{ Data collection } \\
\hline Space group & $P 22_{1} 2_{1}$ & $P 22_{1} 2_{1}$ \\
\hline \multicolumn{3}{|l|}{ Cell dimensions } \\
\hline$a, b, c(\AA)$ & $88.0,89.3,134.4$ & $90.4,91.7,139.3$ \\
\hline$\alpha, \beta, \gamma\left(^{\circ}\right)$ & $90,90,90$ & $90,90,90$ \\
\hline Wavelength $(\AA)$ & 1.033 & 1.283 \\
\hline Resolution ( $\AA$ ) & $44.6-2.24(2.32-2.24)$ & $45.8-2.59(2.68-2.59)^{C}$ \\
\hline$R_{\text {merge }}$ & $0.128(2.58)$ & $0.086(1.08)$ \\
\hline$R_{\mathrm{PIM}}$ & $0.03(0.50)$ & $0.04(0.45)$ \\
\hline$R_{\text {meas }}$ & $0.13(2.63)$ & $0.09(1.16)$ \\
\hline$|/ \sigma|$ & 15.8 (1.09) & $15.7(1.75)$ \\
\hline Completeness (\%) & $1.00(0.99)$ & $1.00(0.99)$ \\
\hline Redundancy & $27.1(26.4)$ & $7.1(6.7)$ \\
\hline $\mathrm{CC}_{1 / 2}$ & $1(0.48)$ & $1(0.64)$ \\
\hline
\end{tabular}

Refinement

No. of reflections $\quad 51,313$

No. of atoms

Protein

RNA

$\mathrm{Zn}$

Water

Average $B$-factor $\left(\AA^{2}\right)$

Protein

RNA

$\mathrm{Zn}$

Water

R.m.s deviations

Bond lengths $(\AA)$

Bond angles $\left(^{\circ}\right)$

Data merged from two crystals

Anomalous pairs were kept separate for calculating statistics

'Values in parentheses pertain to the outermost shell of data

surrounding the primer-binding site were prominent sites of $\mathrm{A} 3 \mathrm{H}$ binding (Fig. 5a). This portion of the genome contains extensive RNA duplexes, including the genome-transfer RNA primer complex $^{32}$. A similar CLIP analysis of huA3H and the three pgtA3H protein variants collected from infected cells rather than virions (Supplementary Fig. 10a) also indicated a statistically significant preference for areas in the viral genome that contain potential duplexes of $\geq 7 \mathrm{nt}$ (Supplementary Fig. 10b). Comparison of the nucleotide compositions of favored binding sites (peaks) vs. disfavored sites (valleys) indicated relative enrichment of G-nucleotides in peaks (even though the HIV-1 genome is Arich) and A-nucleotides in valleys (Supplementary Fig. 11). This characteristic is consistent with the notion that $\mathrm{A} 3 \mathrm{H}$ favors binding to transiently formed duplexes, promoted in G-rich regions by the ability of $\mathrm{G}$ to pair with both $\mathrm{U}$ and $\mathrm{C}$, in otherwise predominantly ssRNA molecules.

\section{Discussion}

We found an unusually high degree of polymorphism in $\mathrm{A} 3 \mathrm{H}$ proteins in a non-human species and have demonstrated that all variants exhibit potent antiviral activity. Importantly, this polymorphism allowed the identification of a naturally occurring $\mathrm{A} 3 \mathrm{H}$ protein that is amenable to crystallization. We have determined the structure of a full-length, unaltered, APOBEC3 protein with antiviral activity. Furthermore, A3H unexpectedly cocrystallized with duplex RNA, thus the structure, in combination with CLIP-seq data, illuminates how $\mathrm{A} 3 \mathrm{H}$ could be encapsidated into virions and how it inhibits viral replication independent of cytidine deamination ${ }^{13}$.

An understanding of how APOBEC3 proteins are specifically incorporated into virions has been elusive, given their apparent

lack of specificity in recognition of RNA sequences, and the abundance of cellular RNAs in the cytoplasm, only a tiny fraction of which are packaged into virions. Our data favor a model in which the $\mathrm{A} 3 \mathrm{H}$ protein preferentially binds to short RNA duplexes with little or no primary sequence discrimination during encapsidation. While other binding modes may be possible, favoring short duplex RNA in this manner might provide selectivity for viral RNA molecules that are in the act of compacting during virion packaging. Selective binding to only a sample of all possible RNA sequences, that is, those that are capable of duplex formation, should also reduce the effect of "distracting" cellular RNAs. It is also noteworthy that the observed prominent binding in the structured $5^{\prime}$ leader would position $\mathrm{A} 3 \mathrm{H}$ optimally for the inhibition of reverse transcription ${ }^{13}$. As the $5^{\prime}$ leader is the most frequently bound site within the HIV-1 genome in virions, this could account for the deaminase-independent antiviral activity of $\mathrm{A} 3 \mathrm{H}^{13}$. Intriguingly, the $\mathrm{A} 3 \mathrm{H}-\mathrm{RNA}$-binding mode is equally relevant to an RNA-DNA heteroduplex (Supplementary Fig. 7b) such as the initial product of reverse transcription in which the RNA strand is cleaved at $\sim 6$-nt intervals by RNase $\mathrm{H}^{33}$. The active site for cytidine deamination is near to the RNA $5^{\prime}$ end (Fig. $4 \mathrm{~b}, \mathrm{c}$ ), suggesting that $\mathrm{A} 3 \mathrm{H}$ binding to the RNA-DNA heteroduplex product of reverse transcription may be an evolved property that facilitates delivery of DNA to the active site.

Our results demonstrate that, while ribonuclease treatment increased the rate of deamination by twofold (Supplementary Fig. 3c), it is not essential to the deaminase activity of purified $\mathrm{A} 3 \mathrm{H}$. This is in contrast to Mitra et al. ${ }^{13}$, who found that RNase A treatment was required for activity of huA3H in mammalian cell extracts. Thus, it is likely that purification-with or without ribonuclease treatment-removed interfering RNA molecules and that the RNA fragments remaining bound to $\mathrm{A} 3 \mathrm{H}$ do not significantly inhibit activity.

APOBEC3 family members are composed of $\mathrm{Z}$ domains of similar overall structure (Supplementary Fig. 4a), including a highly conserved characteristic Zn-binding site. Nevertheless, in double domain APOBEC3 proteins, such as $\mathrm{A} 3 \mathrm{G}$ and $\mathrm{A} 3 \mathrm{~F}$, each domain has adopted a distinct function in which the N-terminal domain (NTD) binds viral RNA and the C-terminal domain (CTD) exhibits enzymatic activity. Furthermore, while the NTD in A3G is targeted by Vif, the CTD is targeted in $\mathrm{A} 3 \mathrm{~F}^{18,34}$. In contrast, in $\mathrm{A} 3 \mathrm{H}$, a single domain exhibits all these functions. Multiple $\mathrm{A} 3 \mathrm{H}$ residues that cluster on the surface of helices $\alpha 3$ and $\alpha 4$ have been implicated in Vif binding (Supplementary Fig. 5). A3H polymorphism in humans appears to have driven HIV-1 Vif evolution ${ }^{35,36}$. Interestingly, HIV1 Vif does not recognize macaque $\mathrm{A} 3 \mathrm{H}$, while $\mathrm{HIV}-2$ and SIVmac Vif $\mathrm{do}^{3-5}$. Residues that differ between human and macaque $\mathrm{A} 3 \mathrm{H}$ (Supplementary Fig. 1) are scattered across the protein surface. It will be interesting to determine which of these residues governs differential Vif recognition.

Despite the similarities in overall structure with other members of the APOBEC3 family and the strongly basic character of the RNA-binding $\mathrm{Z}$ domains (A3H, A3F NTD, A3G NTD), the unusual mode of RNA binding by $\mathrm{A} 3 \mathrm{H}$ appears to be distinct. Indeed, the 10 most frequent A3G-binding sites in HIV-1 virion RNA were significantly less likely to contain predicted, overlapping $\geq 7 \mathrm{nt}$ duplexes than were the preferred $\mathrm{A} 3 \mathrm{H}$-binding sites $(p=0.033$, Fig. 5c). In addition, whereas all $\mathrm{A} 3 \mathrm{H}$ variants bind strongly to the $5^{\prime}$ leader of the viral genome (Fig. 5a, Supplementary Figs. 9, 10), A3G does not, and the overall distribution of peaks and valleys in virions differs between the two proteins ${ }^{8}$. Accordingly, RNA-binding features in A3H (Fig. 4), particularly a loop 1 insertion that contacts the RNA narrow major groove and the overall surface charge distribution, are clearly different from the A3G NTD (Fig. 5d, Supplementary Fig. 12). Identical basic surfaces of two A3H molecules contact a short RNA duplex to 
a
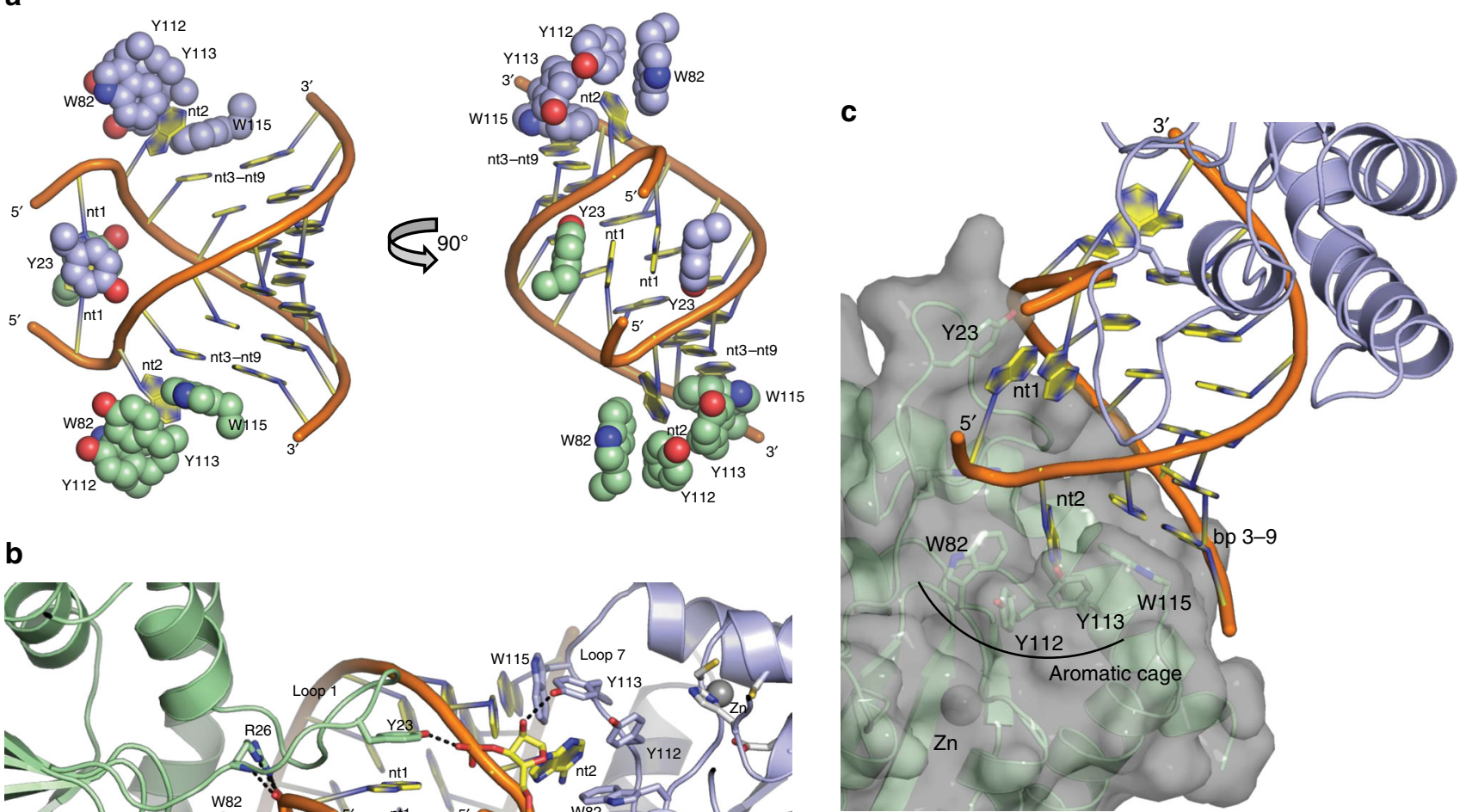

b

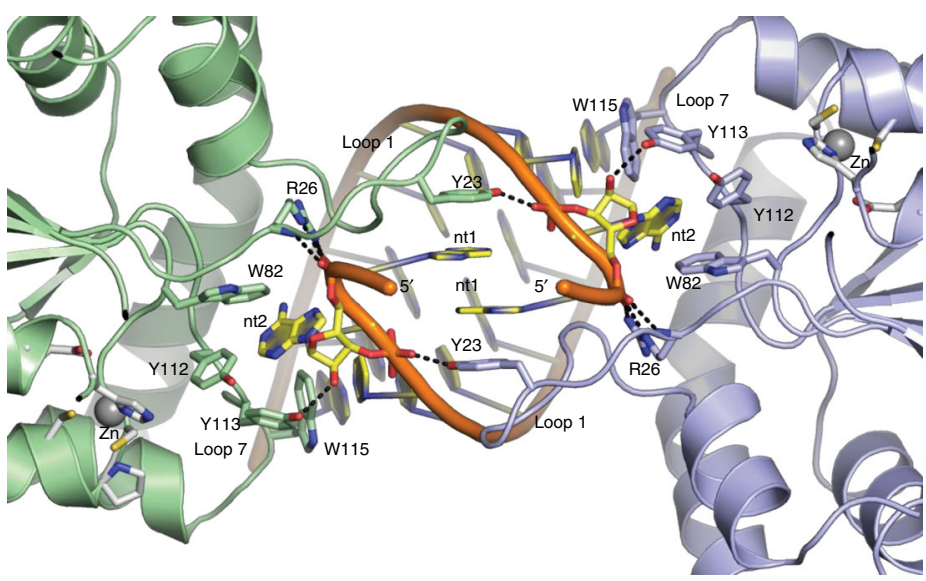

Fig. 4 Unusual A3H-RNA interaction. a Aromatic amino acids (spheres with C colored as in Fig. 2a) that contact RNA bases (cartoon). The nt1 bases stack with each other and with Tyr23, the nt2 bases are bound in an "aromatic cage", and the nt3-nt9 base pairs stack with Trp115. b Loop 1 protrusion into the RNA narrow major groove. Key amino acids and nucleotides are shown in stick form (green or light blue $\mathrm{C}$, red $\mathrm{O}$, blue $\mathrm{N}$, orange $\mathrm{P}$ ) with hydrogen bonds (dashed lines) from Tyr23, Arg26, and Tyr113 to the RNA. Side chains in the active sites are shown in stick form with white $\mathrm{C}$ atoms and Zn ions as gray spheres and correspond to the zinc-dependent deaminase signature motif $(\mathrm{C} / \mathrm{H}) \times \mathrm{E}(\mathrm{x})_{n} \mathrm{PC} \times \mathrm{xC}$ (His54, Glu56, Pro84, Cys85, Cys88). c Surface view of one $\mathrm{A} 3 \mathrm{H}$ molecule showing the pocket formed by the "aromatic cage" for the unpaired nt2 base and the nearby active site entrance

form an A3H-RNA complex, whereas the analogous A3G NTD surface is hydrophobic and forms a protein dimer ${ }^{22}$, strongly suggesting heterogeneity in the ways in which different A3 proteins recognize RNA.

Overall, the A3H:RNA complex structure presented herein provides an unexpected view of an unusual RNA-binding mode for $\mathrm{A} 3 \mathrm{H}$ and illuminates potential mechanisms of antiviral activity.

\section{Methods}

Identification of APOBEC3H variants in pig-tailed macaques. Total RNA and genomic DNA were extracted from 14 activated, IFN $\alpha$-treated pig-tailed macaque peripheral blood mononuclear cell samples using TRIZOL (GibcoBRL). Thereafter, complementary DNA (cDNA) was synthesized using the SuperScript III RT kit (Invitrogen) using gene-specific primers (Supplementary Table 1) based on the rhesus macaque A3H sequence (NM_001042372). Two independent PCR reactions were performed on each cDNA sample, introduced into pCR-Blunt (Invitrogen) and a total of 12-26 clones were analyzed by sequencing. Selected clones were subcloned into a modified LHCX (Clontech) vector, that expresses hygromycin, such that the $\mathrm{A} 3 \mathrm{H}$ stop codon was removed and three copies of an HA tag were fused to the $\mathrm{C}$-terminus of the protein $(\mathrm{A} 3 \mathrm{H}-3 \mathrm{xHA})^{8}$. Next, $800 \mathrm{ng}$ of each $\mathrm{A} 3 \mathrm{H}-3 \mathrm{xHA}$ expressing plasmid or the LHCX control plasmid were co-transfected in 293T cells (ATCC) $\left(8 \times 10^{5}\right.$ cells per well-six-well) using $12 \mu \mathrm{L}$ polyethylenimine (PEI) (Polysciences, Inc.) together with $800 \mathrm{ng}$ of a murine leukemia virus (MLV) GagPol expression plasmid and $100 \mathrm{ng}$ of a vesicular stomatitis virus glycoprotein (VSV.G) expression plasmid to produce MLVbased retroviral stocks, which were subsequently used to transduce $293 \mathrm{~T}$ cells. Cells stably expressing each pig-tailed $\mathrm{A} 3 \mathrm{H}$ (pgtA3H) variant were selected and maintained in medium containing hygromycin $(10 \mathrm{ng} / \mathrm{mL})^{8}$.

Virion incorporation assay. $293 \mathrm{~T}$ cells stably expressing huA3H or pgtA3H variants $\left(7 \times 10^{5}\right.$ cells per well-six-well) were infected with VSV.G pseudotyped HIV- $1_{\text {NLA.3AVif }}$ at a multiplicity-of-infection (MOI) of 2 . At $16 \mathrm{~h}$ post infection, supernatants were collected, clarified by centrifugation at $748 \times g$, filtered through a $0.22 \mu \mathrm{m}$ filter, and virions were purified via ultracentrifugation through a $25 \%$ sucrose cushion. Supernatants from uninfected $\mathrm{A} 3 \mathrm{H}$-expressing cells were used as control for specificity of $\mathrm{A} 3 \mathrm{H}$ incorporation into viral particles. Purified virions and cell lysates were analyzed by immunoblot using a rabbit anti-HA at a 1:1000 dilution (600-401-384 Rockland) and a mouse anti-HIV-1 p24 capsid at a 1:100 dilution (183-H12-5C, NIH AIDS Reagent Program) antibodies, followed by an anti-rabbit IgG conjugated to IR Dye680 and an anti-mouse IgG conjugated to IR Dye800 (LiCOR).

Antiviral activity assay for $\mathbf{A} 3 \mathbf{H}$ variants. $293 \mathrm{~T}$ cells $\left(5 \times 10^{4}\right.$ cell per well- 96 well) were transfected using $2 \mu \mathrm{L}$ PEI (Polysciences, Inc.) with $50 \mathrm{ng}$ of an HIV$1_{\mathrm{NL} 4.3 \Delta \mathrm{V} \text { if }}$ proviral plasmid, $12 \mathrm{ng}$ of a VSV.G expression plasmid, and $0,37.5,75$, or $150 \mathrm{ng}$ of each $\mathrm{A} 3 \mathrm{H}-3 \mathrm{xHA}$ expression plasmid using the LHCX plasmid as filler to maintain a constant total amount of DNA per transfection. At $48 \mathrm{~h}$ post transfection, supernatant was collected, frozen at $-70^{\circ} \mathrm{C}$ and then thawed and titrated on Helios indicator cells that constitutively express CD4 and CCR5 and also express a nanoluciferase gene under the control of the HIV-2 LTR. At $48 \mathrm{~h}$ post inoculation, infectivity was quantified by measuring nanoluciferase expression using the Nano-Glo Luciferase assay (Promega) and is expressed as Relative Light Units (RLU). 


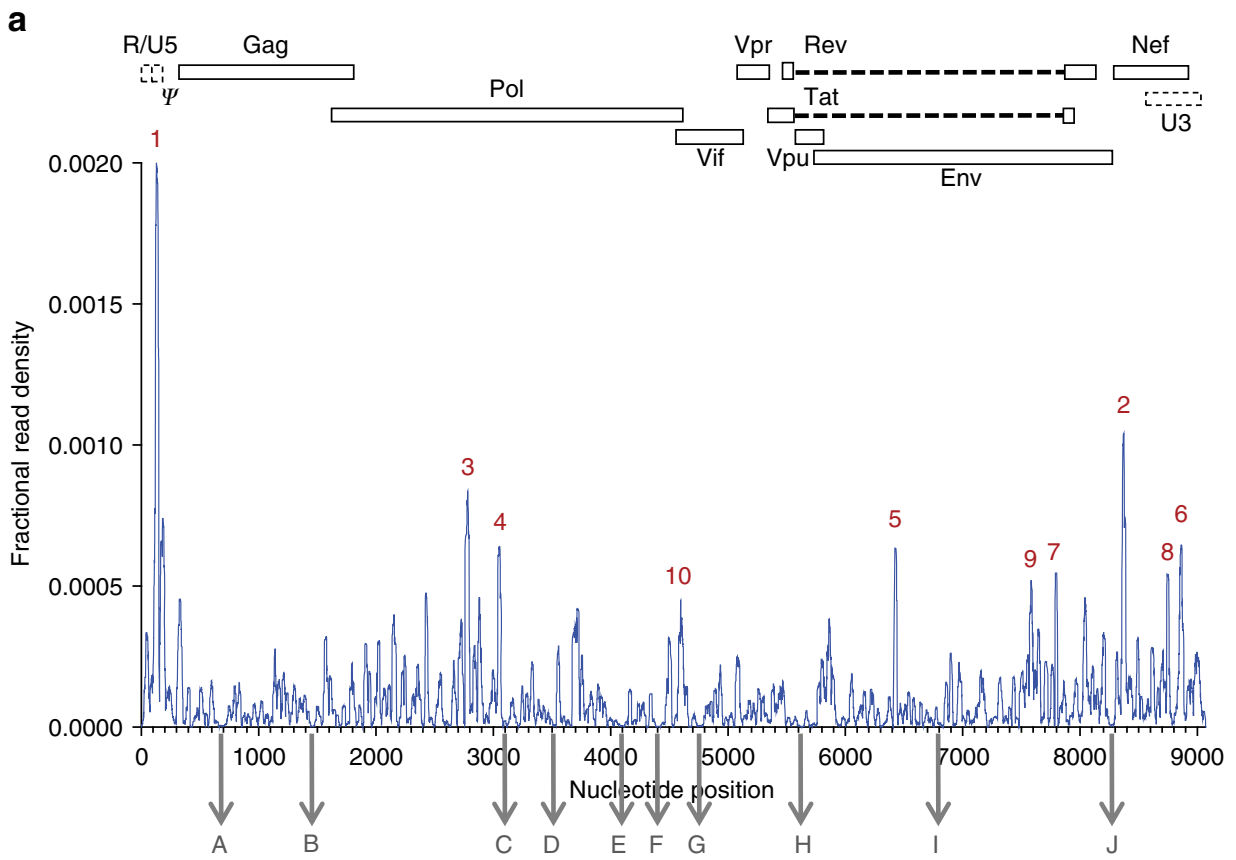

b

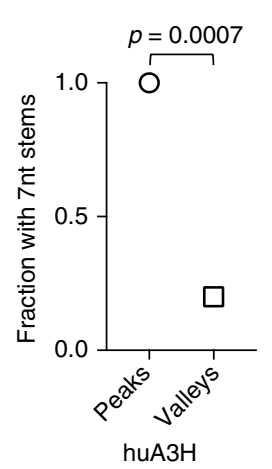

c

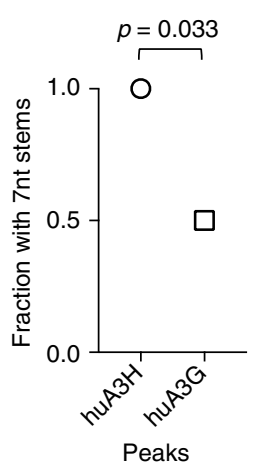

d

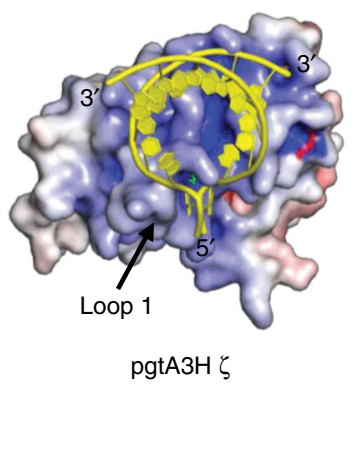

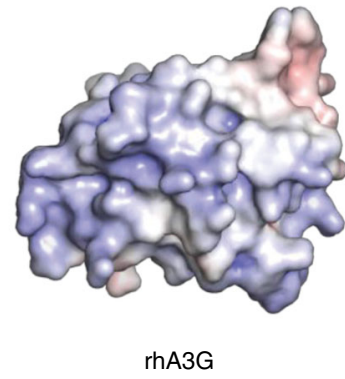

RNA-binding domain

Fig. 5 Analysis of $\mathrm{A} 3 \mathrm{H}$ binding to the HIV-1 genome. a Frequency distribution of nucleotide occurrence (read density) relative to the sum of read densities in reads mapped to the HIV-1 NL4-3 genome in a huA3H CLIP-Seq experiment using HIV-1 particles ${ }^{8}$. The 10 most frequently (designated 1-10 for highest to lowest fractional read density) and 10 least frequently bound sites (designated A-J for relative position in the viral genome) are indicated. A schematic diagram of the HIV-1 genome is shown above. b Frequency with which $\geq 7$-nt duplexes are predicted to occur within 101-nt RNA elements containing the 10 sites with high-frequency binding (peaks 1-10), and 101-nt elements with low-frequency binding (valleys A-J). c Frequency with which $\geq 7$-nt duplexes are predicted to occur within 101-nt RNA elements containing the 10 sites most frequently bound by A3H and A3G. d Comparison of surface charge distribution for $\mathrm{A} 3 \mathrm{H}$ and the A3G RNA-binding domain. RNA (yellow cartoon) binds to the most positively charged surface of $\mathrm{A} 3 \mathrm{H}$ (electrostatic surface potential colored from red to blue, -10 to $+10 \mathrm{kT} / \mathrm{e}$ ). The analogous surface of the A3G RNA-binding domain (PDB $5 \mathrm{~K} 81^{22}$ ) is relatively hydrophobic

Expression of $\mathbf{A} \mathbf{3}$ protein variants. Recombinant huA3H, three pgtA3H variants $(\alpha, \eta, \zeta)$, and catalytically inactive pgtA $3 \mathrm{H} \alpha \mathrm{E} 56 \mathrm{~A}^{13}$ were produced in $E$. coli using codon-optimized synthetic DNAs (Supplementary Table 1). Ligationindependent cloning (LIC) was used with the expression vectors pMCSG7 ${ }^{37}(\mathrm{~N}-$ terminal $\mathrm{His}_{6}$ tag and tobacco etch virus (TEV) protease cleavage site), including all pgtA3H variants, or $\mathrm{pMocr}^{38}$ ( $\mathrm{N}$-terminal $\mathrm{His}_{6}$ tag, Mocr, and TEV cleavage site) for huA3H. All sequences were confirmed by Sanger sequencing. Plasmids phA3H001 and ppgtA3H001-003 were transformed into E. coli strain BL21(DE3) carrying the pGro7 plasmid for co-expression of chaperones GroES-GroEL (Takada $^{39}$. Transformed cells were grown in $4 \%$ glycerol terrific broth media at 37 ${ }^{\circ} \mathrm{C}$ until the $\mathrm{OD}_{600}$ reached 0.6-0.8. Chaperone expression was induced with Larabinose $(1 \mathrm{~g} / \mathrm{L})$ at $37^{\circ} \mathrm{C}$ for $1 \mathrm{~h}$, then cultures were cooled to $20^{\circ} \mathrm{C}$, induced with $200 \mu \mathrm{M}$ IPTG, and grown overnight. Cells were collected via centrifugation and stored at $-20^{\circ} \mathrm{C}$.

Mutagenesis. The catalytically inactive variant of pgtA3H $\alpha$ was generated by PCR and confirmed by sanger sequencing. Primers were designed with the Quikchange primer design tool website (Agilent) and are included in Supplementary Table 1 .
Protein purification. Bacterial cell pellets were resuspended in buffer A $(50 \mathrm{mM}$ Tris $\mathrm{pH} 8.5,300 \mathrm{mM} \mathrm{NaCl}, 10 \%$ glycerol, $5 \mathrm{mM} \beta$-mercaptoethanol) with $2 \mathrm{mM}$ $\mathrm{MgCl}_{2}, 0.5 \mathrm{mg} / \mathrm{mL}$ DNaseI, $0.5 \mathrm{mg} / \mathrm{mL}$ RNase A, and $0.1 \mathrm{mg} / \mathrm{mL}$ lysozyme (lysis conditions). Under these conditions, resuspended cells from a 1-L culture were incubated on ice for at least $1 \mathrm{~h}$, followed by sonication. Supernatants of centrifuged cell lysates were batch-bound to $5 \mathrm{~mL}$ Ni-NTA resin (Qiagen) overnight at $4^{\circ} \mathrm{C}$. The resin was washed with 5 column volumes (CVs) of buffer A followed by a 5-CV wash using buffer A with $1 \mathrm{M} \mathrm{NaCl}$ and $20 \mathrm{mM}$ imidazole. Protein was eluted with 6-CV buffer A with $200 \mathrm{mM}$ imidazole. Purification tags were removed by overnight incubation with TEV protease $(+2 \mathrm{mM}$ dithiothreitol (DTT)) in dialysis against buffer A. Tag-free protein was separated from uncleaved protein and TEV protease with a $5 \mathrm{~mL}$ His Trap column (GE Healthcare), and the flow-through was concentrated and incubated for $4 \mathrm{~h}$ with $1 \mathrm{mg} / \mathrm{mL}$ RNase A at $25^{\circ} \mathrm{C}$. Attempts to remove nucleic acid from the protein, including PEI precipitation, were unsuccessful, however with extensive RNase A treatment, a monodisperse chromatogram was achieved. Concentrated protein was loaded onto a Superdex 16/60 S200 gel filtration column and eluted in $50 \mathrm{mM}$ Tris $\mathrm{pH} 8,150 \mathrm{mM} \mathrm{NaCl}, 5 \%$ glycerol, $1 \mathrm{mM}$ Tris(2-carboxyethyl)phosphine. All APOBEC3H proteins eluted as monodisperse complexes with an apparent molecular weight (MW) of $60 \mathrm{kDa}$ (calculated A3H MW $=25.2 \mathrm{kDa}$ ). Peak fractions were pooled, concentrated to $10 \mathrm{mg} / \mathrm{mL}$, and flash-frozen in liquid $\mathrm{N}_{2}$. All purified proteins, despite removal efforts, contained 
nucleic acid as shown by the absorbance ratio $\left(A_{260 \mathrm{~nm}} / A_{280 \mathrm{~nm}}\right)$ of 1.5 . Tag-free protein was used for all biochemical and crystallographic experiments. No RNase A was used in the purification of proteins for the assay data shown in Supplementary Fig. 3c.

Nucleic acid extraction and denaturing gel electrophoresis. Nucleic acid was extracted from each $\mathrm{A} 3 \mathrm{H}$ preparation after the gel filtration step using a phenol: chloroform extraction followed by ethanol precipitation $(95 \%$ ethanol for $2 \mathrm{~h}$ at $\left.-20^{\circ} \mathrm{C}\right)^{40,41}$. Extracted nucleic acids from each $\mathrm{A} 3 \mathrm{H}$ preparation were separated on a $15 \%$ urea polyacrylamide denaturing gel followed by overnight staining with Stains All (Sigma) to determine the identity of the bound nucleic acid (purple RNA, blue DNA) and its approximate size (by comparison to defined oligonucleotides of length $30,20,17$, and $10 \mathrm{nt})$.

Cytidine deaminase assay. Cytidine deaminase activity was evaluated in a coupled assay with uracil-DNA glycosylase (UDG) ${ }^{26,42}$. Recombinant $\mathrm{UDG}^{43}$ was produced in E. coli from pUDG001 generated by LIC of a synthetic DNA (Supplementary Table 1) into pMCSG7, and purified by Ni-affinity chromatography. The substrate was a 40-nt ssDNA oligomer containing one deoxycytosine and a 5 fluorescent tag (6-carboxyfluorescein, 6-FAM): 5'-(6-FAM) AATGAAAGATATAAGACTCAAATTGAAATAGTTAAGATTA-3'. Reaction mixtures (total volume $4 \overline{\mu \mathrm{L}}$ ) contained $1 \mu \mathrm{M}$ DNA substrate, $40 \mathrm{nM}$ UDG, $50 \mathrm{mM}$ Tris $\mathrm{pH}$ 7.5, $40 \mathrm{mM} \mathrm{NaCl}, 5 \mathrm{mM} \mathrm{MgCl} 2,1 \mathrm{mM} \mathrm{DTT}$, and $4 \mathrm{nM}, 20 \mathrm{nM}$ or $100 \mathrm{nM} \mathrm{A} 3 \mathrm{H}$. Reactions at $37^{\circ} \mathrm{C}$ were initiated by addition of $\mathrm{A} 3 \mathrm{H}$. At each time point, the reaction was quenched with two volumes of $0.2 \mathrm{M} \mathrm{NaOH}$ followed by heating $15 \mathrm{~min}$ at $70^{\circ} \mathrm{C}$ to hydrolyze DNA at the deglycosylated nucleotide. After addition of three volumes of formamide loading solution, the samples were heated $10 \mathrm{~min}$ at $95^{\circ} \mathrm{C}$, and the products were resolved by $15 \%$ urea denaturing polyacrylamide gel electrophoresis. Gels were scanned using a Typhoon fluorescence imager, and bands corresponding to cleaved and uncleaved DNA were quantified using the ImageQuant software (GE Healthcare Life Sciences). To confirm that $\mathrm{Zn}$ was not limiting in the deaminase assay, parallel experiments were performed as described above with or without addition of 2 and $10 \mu \mathrm{M} \mathrm{ZnCl}_{2}$ to the assay buffer ( $2 \times$ and $10 \times$ molar excess of $\mathrm{A} 3 \mathrm{H})$. Activities were identical within experimental error (Supplementary Fig. 3b).

Crystallography. Crystals of the full-length pgtA $3 \mathrm{H} \zeta(10 \mathrm{mg} / \mathrm{mL})$ were grown at $20^{\circ} \mathrm{C}$ by sitting-drop vapor diffusion from a 2:1 mixture of protein stock and reservoir solution (28\% polyethylene glycol average MW 4000, $0.1 \mathrm{M} \mathrm{MgCl}_{2}, 0.1 \mathrm{M}$ Tris $\mathrm{pH}$ 8.5). Crystals grew in 1-2 days, were collected directly from the growth solution, and were flash-cooled in liquid $\mathrm{N}_{2}$. Data were collected at the Advanced Photon Source (APS, Argonne National Laboratory) on GM/CA beamline 23ID-B. Anomalous pair data to $2.6 \AA$ were recorded at the X-ray energy of peak absorption $(9.667 \mathrm{keV})$ above the $\mathrm{Zn} \mathrm{K}$-edge $(9.6586 \mathrm{keV})$ in $15^{\circ}$ wedges with inverse-beam geometry. Additional data to $2.24 \AA$, recorded from two crystals, were collected at an X-ray energy of $12 \mathrm{keV}$. Data were indexed, integrated, and scaled using XDS ${ }^{44}$. Initial crystal screening suggested the possibility of a tetragonal space group $(a \approx b)$, and we retained these axial assignments throughout the structure determination, which resulted in a nonstandard primitive orthorhombic space group $\left(P 22_{1} 2_{1}\right)$. Anomalous differences to $3.5 \AA$ were used with AutoSol ${ }^{45}$ in the Phenix suite ${ }^{46}$ to determine the $\mathrm{Zn}$ substructure, and for initial single-wavelength anomalous phasing. Phases were refined and extended to $2.6 \AA$ by exploiting the fourfold noncrystallographic symmetry using $\mathrm{DM}^{47}$. A $78 \%$ complete initial model of the protein was built into the 2.6 - $\AA$ phase-refined map using AutoBuild, and the remainder of the model, including an RNA duplex, was built manually in $\cot ^{48}$. Although the RNA density was consistent with a mixture for the base paired nucleotides (nt3-9) and for nt2, for simplicity, the RNA strands were modeled with unique sequences (5'-A-A-C-C-C-G-G-G-G-3' and $\left.5^{\prime}-\mathrm{A}-\mathrm{A}-\mathrm{C}-\mathrm{C}-\mathrm{C}-\mathrm{C}-\mathrm{G}-\mathrm{G}-\mathrm{G}-3^{\prime}\right)$. The ntl nucleotide had clear purine density and was modeled as adenine. For two of the RNA strands, weak density extended beyond nt9, and the ribose for an nt10 was included in the model. The model was refined against the 2.24- $\AA$ data using phenix.refine ${ }^{49}$. Structure validation was done with MolProbity ${ }^{50}$. In the final model, $98 \%$ of amino acids are in favored regions of the Ramachandran plot, $2 \%$ in additionally allowed regions, and none are outliers. Structure images were prepared with PyMOL ${ }^{51}$, electrostatic surface potentials calculated with $\mathrm{APBS}^{52,53}$, and buried surface areas calculated with PISA ${ }^{54-56}$.

CLIP-seq analysis. CLIP-seq analyses ${ }^{8,57}$ were conducted using $293 \mathrm{~T}$ cells stably expressing $3 \times$ HA-tagged pgtA3H proteins. Cells were infected with VSV.G pseudotyped HIV-1 $1_{\mathrm{NL} 4-3} \Delta \mathrm{Vif}$ at an MOI of 2 and fed with 4-thiouridine (4SU; Sigma) $14 \mathrm{~h}$ prior to collection. Thereafter, cells and virions were irradiated, lysed in NP-40 lysis buffer, and the soluble fraction was separated by centrifugation. Lysates were subsequently treated with RNase A (Fermentas) and DNaseI (Roche) and then transferred to ice. Protein G-conjugated magnetic Dynabeads coated with a mouse monoclonal anti-HA antibody were added to lysates. After binding, the beads were washed thoroughly ${ }^{8,57}$. Dephosphorylation was done using calfintestinal phosphatase (NEB), and the beads were then washed and resuspended in 1 bead volume of polynucleotide kinase (PNK) buffer, $\left[\gamma_{-}{ }^{32} \mathrm{P}\right]$ ATP and T4 PNK (NEB). Cold ATP was added and the phosphorylation reaction continued. The beads were then washed and resuspended in NuPAGE SDS-PAGE loading buffer to elute protein-RNA adducts. Protein-RNA adducts were separated by SDSPAGE, transferred to nitrocellulose and detected by autoradiography. RNA was isolated by proteinase K treatment and phenol:chloroform extraction ${ }^{8,57}$. Sequential $3^{\prime}$ and $5^{\prime}$ adapter ligations were then performed on the isolated RNA resulting in RNA of unknown sequence that was flanked by known sequence that contained primer-binding sites for subsequent reverse transcription and PCR-amplification of the cDNA library. Sequencing of the cDNA library was performed on an Illumina HiSeq 2000 platform. The analysis pipeline used the FASTX toolkit (http:// hannonlab.cshl.edu/fastx_toolkit/) to process the raw reads prior to mapping them to the HIV-1 viral genome ${ }^{8,57}$. Preferred A3H-binding sites in the viral genome (Peaks) were identified as the positions of the HIV-1 genome with the highest read densities. The 10-12 highest peaks were identified for each A3H protein. Thereafter, 50 nucleotides on either side of the nucleotide with the highest read density value were selected for further analysis. Potential RNA duplexes were detected using $\mathrm{M}$-fold ${ }^{58}$ with default parameters. An equal number of regions with low frequencies of $\mathrm{A} 3 \mathrm{H}$ binding (Valleys) were identified as 101-nucleotide stretches in the HIV-1 genome with low read density $(<200)$ and subjected to the same analysis as the peaks. To determine the nucleotide composition of the tips of the peaks, the nucleotides with the highest read density within a peak were selected and the base composition determined. For comparison, we identified short valleys as stretches of nucleotides with identical length to the peak tips in a proximal region of the HIV-1 genome. In each CLIP-seq experiment, approximately two to three peaks had wide tips that rendered the identification of short valleys in the vicinity of those peaks impossible, and therefore distal regions of the genome were used.

Data availability. Atomic coordinates and structure factors have been deposited in the Protein Data Bank (PDB) database under the accession code 5W3V. The pgtA3H variant sequences identified in these studies have been deposited to GenBank (accession numbers MF509624 through MF509631). Other data are available from the corresponding authors upon reasonable request.

Received: 26 May 2017 Accepted: 6 September 2017

Published online: 18 October 2017

\section{References}

1. Sheehy, A. M., Gaddis, N. C., Choi, J. D. \& Malim, M. H. Isolation of a human gene that inhibits HIV-1 infection and is suppressed by the viral Vif protein. Nature 418, 646-650 (2002).

2. Refsland, E. W. \& Harris, R. S. The APOBEC 3 family of retroelement restriction factors. Curr. Top. Microbiol. Immunol. 371, 1-27 (2013).

3. Mariani, R. et al. Species-specific exclusion of APOBEC3G from HIV-1 virions by Vif. Cell 114, 21-31 (2003).

4. OhAinle, M., Kerns, J. A., Malik, H. S. \& Emerman, M. Adaptive evolution and antiviral activity of the conserved mammalian cytidine deaminase APOBEC3H. J. Virol. 80, 3853-3862 (2006).

5. Virgen, C. A. \& Hatziioannou, T. Antiretroviral activity and Vif sensitivity of rhesus macaque APOBEC3 proteins. J. Virol. 81, 13932-13937 (2007).

6. Zennou, V., Perez-Caballero, D., Gottlinger, H. \& Bieniasz, P. D. APOBEC3G incorporation into human immunodeficiency virus type 1 particles. J. Virol. 78, 12058-12061 (2004).

7. Schafer, A., Bogerd, H. P. \& Cullen, B. R. Specific packaging of APOBEC3G into HIV-1 virions is mediated by the nucleocapsid domain of the gag polyprotein precursor. Virology 328, 163-168 (2004).

8. York, A., Kutluay, S. B., Errando, M. \& Bieniasz, P. D. The RNA binding specificity of human APOBEC3 proteins resembles that of HIV-1 nucleocapsid. PLoS Pathog. 12, e1005833 (2016).

9. Apolonia, L. et al. Promiscuous RNA binding ensures effective encapsidation of APOBEC3 proteins by HIV-1. PLoS Pathog. 11, e1004609 (2015).

10. Newman, E. N. et al. Antiviral function of APOBEC3G can be dissociated from cytidine deaminase activity. Curr. Biol. 15, 166-170 (2005).

11. Iwatani, Y. et al. Deaminase-independent inhibition of HIV-1 reverse transcription by APOBEC3G. Nucleic Acids Res. 35, 7096-7108 (2007).

12. Bishop, K. N., Verma, M., Kim, E. Y., Wolinsky, S. M. \& Malim, M. H. APOBEC3G inhibits elongation of HIV-1 reverse transcripts. PLoS Pathog. 4, e1000231 (2008).

13. Mitra, M. et al. Sequence and structural determinants of human APOBEC3H deaminase and anti-HIV-1 activities. Retrovirology 12, 3 (2015).

14. Huthoff, H., Autore, F., Gallois-Montbrun, S., Fraternali, F. \& Malim, M. H. RNA-dependent oligomerization of APOBEC3G is required for restriction of HIV-1. PLoS Pathog. 5, e1000330 (2009).

15. Li, J. et al. APOBEC3 multimerization correlates with HIV-1 packaging and restriction activity in living cells. J. Mol. Biol. 426, 1296-1307 (2014).

16. McDougall, W. M. \& Smith, H. C. Direct evidence that RNA inhibits APOBEC3G ssDNA cytidine deaminase activity. Biochem. Biophys. Res. Commun. 412, 612-617 (2011). 
17. Belanger, K., Savoie, M., Rosales Gerpe, M. C., Couture, J. F. \& Langlois, M. A. Binding of RNA by APOBEC $3 \mathrm{G}$ controls deamination-independent restriction of retroviruses. Nucleic Acids Res. 41, 7438-7452 (2013).

18. Aydin, H., Taylor, M. W. \& Lee, J. E. Structure-guided analysis of the human APOBEC3-HIV restrictome. Structure 22, 668-684 (2014).

19. $\mathrm{Lu}, \mathrm{X}$. et al. Crystal structure of DNA cytidine deaminase ABOBEC3G catalytic deamination domain suggests a binding mode of full-length enzyme to singlestranded DNA. J. Biol. Chem. 290, 4010-4021 (2015).

20. Shaban, N. M., Shi, K., Li, M., Aihara, H. \& Harris, R. S. $1.92 \AA$ zinc-free APOBEC3F catalytic domain crystal structure. J. Mol. Biol. 428, 2307-2316 (2016).

21. Nakashima, M. et al. Structural insights into HIV-1 Vif-APOBEC3F interaction. J. Virol. 90, 1034-1047 (2016).

22. Xiao, X., Li, S.-X., Yang, H. \& Chen, X. S. Crystal structures of APOBEC3G Ndomain alone and its complex with DNA. Nat. Commun. 7, 12193 (2016).

23. Kitamura, S. et al. The APOBEC3C crystal structure and the interface for HIV1 Vif binding. Nat. Struct. Mol. Biol. 19, 1005-1010 (2012).

24. OhAinle, M., Kerns, J. A., Li, M. M. H., Malik, H. S. \& Emerman, M. Antiretroelement activity of APOBEC $3 \mathrm{H}$ was lost twice in recent human evolution. Cell Host Microbe 4, 249-259 (2008).

25. Harari, A., Ooms, M., Mulder, L. C. \& Simon, V. Polymorphisms and splice variants influence the antiretroviral activity of human APOBEC3H. J. Virol. 83 295-303 (2009)

26. Gu, J. et al. Biochemical characterization of APOBEC3H variants: implications for their HIV-1 restriction activity and mC modification. J. Mol. Biol. 428, $4626-4638$ (2016).

27. Feng, Y. et al. Natural polymorphisms and oligomerization of human APOBEC3H contribute to single-stranded DNA scanning ability. J. Biol. Chem. 290, 27188-27203 (2015).

28. Huthoff, H. \& Malim, M. H. Identification of amino acid residues in APOBEC3G required for regulation by human immunodeficiency virus type 1 Vif and Virion encapsidation. J. Virol. 81, 3807-3815 (2007)

29. Zhang, K. L. et al. Model structure of human APOBEC3G. PLoS ONE 2, e378 (2007).

30. Zhen, A., Wang, T., Zhao, K., Xiong, Y. \& Yu, X. F. A single amino acid difference in human APOBEC3H variants determines HIV-1 Vif sensitivity. J. Virol. 84, 1902-1911 (2010).

31. Ooms, M., Letko, M. \& Simon, V. The structural interface between HIV-1 Vif and human APOBEC3H. J Virol 91, doi:10.1128/JVI.02289-16 (2017).

32. Keane, S. C. et al. RNA structure. Structure of the HIV-1 RNA packaging signal. Science 348, 917-921 (2015).

33. Li, A., Li, J. \& Johnson, K. A. HIV-1 reverse transcriptase polymerase and RNase $\mathrm{H}$ (Ribonuclease $\mathrm{H}$ ) active sites work simultaneously and independently. J. Biol. Chem. 291, 26566-26585 (2016).

34. Desimmie, B. A. et al. Multiple APOBEC3 restriction factors for HIV-1 and one Vif to rule them all. J. Mol. Biol. 426, 1220-1245 (2014).

35. Ooms, M. et al. HIV-1 Vif adaptation to human APOBEC3H haplotypes. Cell Host Microbe 14, 411-421 (2013).

36. Gourraud, P. A. et al. APOBEC3H haplotypes and HIV-1 pro-viral vif DNA sequence diversity in early untreated human immunodeficiency virus-1 infection. Hum. Immunol. 72, 207-212 (2011).

37. Stols, L. et al. A new vector for high-throughput, ligation-independent cloning encoding a tobacco etch virus protease cleavage site. Protein Expr. Purif. 25, 8-15 (2002)

38. DelProposto, J., Majmudar, C. Y., Smith, J. L. \& Brown, W. C. Mocr: a novel fusion tag for enhancing solubility that is compatible with structural biology applications. Protein Expr. Purif. 63, 40-49 (2009).

39. Mogk, A., Mayer, M. P. \& Deuerling, E. Mechanisms of protein folding molecular chaperones and their application in biotechnology. Chembiochem 3 , 807-814 (2002).

40. Sambrook, J. \& Russell, D. W. Purification of nucleic acids by extraction with phenol:chloroform. CSH Protoc 2006, https://doi.org/10.1101/pdb.prot4455 (2006).

41. Sambrook, J. \& Russell, D. W. Standard ethanol precipitation of DNA in microcentrifuge tubes. CSH Protoc 2006, https://doi.org/10.1101/pdb.prot4456 (2006).

42. Nair, S. \& Rein, A. In vitro assay for cytidine deaminase activity of APOBEC3 protein. Bio Protoc. 4 (2014).

43. Dmitrochenko, A. E., Turiianskaia, O. M., Gilep, A. A., Usanov, S. A. \& Iantsevich, A. V. An effective scheme to produce recombinant uracil-DNA glycosylase of Escherichia coli for PCR diagnostics. Prikl. Biokhim. Mikrobiol. 50, 398-407 (2014).

44. Kabsch, W. XDS. Acta Crystallogr. D Biol. Crystallogr. 66, 125-132 (2010).

45. Terwilliger, T. C. et al. Decision-making in structure solution using Bayesian estimates of map quality: the PHENIX AutoSol wizard. Acta Crystallogr. D Biol. Crystallogr. 65, 582-601 (2009).
46. Adams, P. D. et al. PHENIX: a comprehensive python-based system for macromolecular structure solution. Acta Crystallogr. D Biol. Crystallogr. 66 , 213-221 (2010).

47. Collaborative Computational Project, Number 4 et al. The CCP4 suite: programs for protein crystallography. Acta Crystallogr. D Biol. Crystallogr. $\mathbf{5 0}$ 760-763 (1994).

48. Emsley, P., Lohkamp, B., Scott, W. G. \& Cowtan, K. Features and development of Coot. Acta Crystallogr. D Biol. Crystallogr. 66, 486-501 (2010).

49. Afonine, P. V. et al. Joint X-ray and neutron refinement with phenix.refine. Acta Crystallogr. D Biol. Crystallogr. 66, 1153-1163 (2010).

50. Chen, V. B. et al. MolProbity: all-atom structure validation for macromolecular crystallography. Acta Crystallogr. D Biol. Crystallogr. 66, 12-21 (2010).

51. Schrodinger, L. The PyMOL molecular graphics system, version 1.8. (2015).

52. Dolinsky, T. J. et al. PDB2PQR: expanding and upgrading automated preparation of biomolecular structures for molecular simulations. Nucleic Acids Res. 35, W522-W525 (2007).

53. Dolinsky, T. J., Nielsen, J. E., McCammon, J. A. \& Baker, N. A. PDB2PQR: an automated pipeline for the setup of poisson-boltzmann electrostatics calculations. Nucleic Acids Res. 32, W665-W667 (2004).

54. Boutselakis, H. et al. E-MSD: the European bioinformatics institute macromolecular structure database. Nucleic Acids Res. 31, 458-462 (2003).

55. Krissinel, E. Macromolecular complexes in crystals and solutions. Acta Crystallogr. D Biol. Crystallogr. 67, 376-385 (2011).

56. Krissinel, E. \& Henrick, K. Inference of macromolecular assemblies from crystalline state. J. Mol. Biol. 372, 774-797 (2007).

57. Kutluay, S. B. et al. Global changes in the RNA binding specificity of HIV-1 gag regulate virion genesis. Cell 159, 1096-1109 (2014).

58. Zuker, M. Mfold web server for nucleic acid folding and hybridization prediction. Nucleic Acids Res. 31, 3406-3415 (2003).

\section{Acknowledgements}

Supported by a grant from the National Institutes of Health (P50GM103297) to JLS, PDB and TH, by the Margaret J. Hunter Collegiate Professorship to JLS, by R01AI078788 to $\mathrm{TH}$, and by R01AI 50111 to PDB. JAB was supported by NIH training grant T32GM008353. Beamlines of GM/CA at APS were supported by the National Institute of General Medical Sciences ("GM", AGM-12006) and the National Cancer Institute (“CA", ACB-12002). We are grateful to Greg DelPrete and Jeff Lifson for providing pigtail PBMC samples.

\section{Author contributions}

T.H., J.L.S. and P.D.B. planned the experiments. J.B. prepared recombinant proteins, performed biochemical assays, and carried out all crystallographic experiments. K.T. performed antiviral activity experiments. A.Y. performed CLIP-seq assays. A.R. characterized $\mathrm{A} 3 \mathrm{H}$ diversity in pigtail macaques. W.C.B. created expression plasmids for A3H variants. All authors analyzed the data. J.B., P.D.B., T.H. and J.L.S. wrote the manuscript.

\section{Additional information}

Supplementary Information accompanies this paper at doi:10.1038/s41467-017-01309-6.

Competing interests: The authors declare no competing financial interests.

Reprints and permission information is available online at http://npg.nature.com/ reprintsandpermissions/

Publisher's note: Springer Nature remains neutral with regard to jurisdictional claims in published maps and institutional affiliations.

\footnotetext{
Open Access This article is licensed under a Creative Commons BY Attribution 4.0 International License, which permits use, sharing,
adaptation, distribution and reproduction in any medium or format, as long as you give appropriate credit to the original author(s) and the source, provide a link to the Creative Commons license, and indicate if changes were made. The images or other third party material in this article are included in the article's Creative Commons license, unless indicated otherwise in a credit line to the material. If material is not included in the article's Creative Commons license and your intended use is not permitted by statutory regulation or exceeds the permitted use, you will need to obtain permission directly from the copyright holder. To view a copy of this license, visit http://creativecommons.org/ licenses/by/4.0/.
}

(C) The Author(s) 2017 